\title{
A Combining Method for Systems Requirement of Knowledge - Based Medical Hazardous Waste
}

\author{
Siti Rohajawati ${ }^{1}$, Sirin Fairus ${ }^{1}$, Hoga Saragih ${ }^{1}$, Habibullah Akbar ${ }^{2}$, Puji Rahayu ${ }^{3}$ \\ ${ }^{1}$ Universitas Bakrie, Jakarta, Indonesia \\ ${ }^{2}$ Universitas Esa Unggul, Jakarta, Indonesia \\ ${ }^{3}$ Universitas Mercu Buana, Jakarta, Indonesia
}

\begin{abstract}
Applying Knowledge-Based Systems (KBS) for hazardous medical waste (HMW) are still limited according to knowledge sources. The two mechanisms of the KBS are commonly known as rulebased and case-based, which can be extracted based on existing regulations that are divided into global, national, provincial, and local authorities. This study used Soft System Methodology and regulation approaches to find out the gaps in coordinating and managing HMW in Indonesia. It is used to depict the rule, processes, and stakeholders for identifying the features of the KBS. The study was taken using fourstage of SSM conducted to classify the objects and their feature requirements. The knowledge source was verified and validated using Focus Group Discussion and represented on CATWOE mode. Most of the regulations are not complying with the practicality of the HMW since it is produced until disposal. The methods give an alternative for knowledge engineers to feed the basis of knowledge.
\end{abstract}

Keywords - Knowledge-Based Systems, SSM, regulation, Hazardous Medical Waste.

DOI: $10.18421 /$ TEM104-37

https://doi.org/10.18421/TEM104-37

Corresponding author: Siti Rohajawati, Universitas Bakrie, Jakarta, Indonesia.

Email: siti.rohajawati@bakrie.ac.id

Received: 08 May 2021.

Revised: 29 October 2021.

Accepted: 03 November 2021.

Published: 26 November 2021.

(c) BY-NC-ND (C) 2021 Siti Rohajawati et al; published by UIKTEN. This work is licensed under the Creative Commons Attribution-NonCommercial-NoDerivs 4.0 License.

The article is published with Open Access at www.temjournal.com

\section{Introduction}

Currently, a KBS have been used widely in the fields such as obesity [1], disaster management [2] [3], and quality improvement in the home [4]. It has been practically applied to solve the various problems using Artificial Intelligence (AI) concept. The AI was raised to be an emerging technology in the last decade. According to [5], the KBS can represent the specific domain problems that are processing deeply the knowledge stored. The system refers to expert systems due to relying expertise, as it is often thought within the human expert knowledge. The two major mechanisms of the KBS are rulebased systems and cased-based systems. Both systems are characterized by the complexity of a domain and higher dynamics. The rule-based relies on predicate logic or a predefined rule set. Whereas the case-based systems are processing on retrieved historical cases in a comparative process through similar case problems. It also can show high diagnostic potential and solve complex problem statements. However, the uses of KBS for HMW are still limited on literature. Meanwhile, the developing countries obtain the challenging of complex problems of hazardous and medical waste.

Indonesia forces the HMW issues to be paid sufficient attention. Similarly with other countries, these are still mixed with domestic wastes and only minor attention is paid to its proper handling until disposal. This condition induces a high risk for health problems of the workers, the public, the municipal cities, and the environment. Whilst the regulations of the HMW have been declared around the world, their wastes are still increased and need significant considering for the last few decades. Moreover, the pandemic of COVID-19 comes to be a crucial problem in healthcare facilities (hospitals). It also depends on numerous factors and is related to the type of hospital establishment and management methods in wastes generation, specifically in managing wastes production. Likewise, the manifest 
of the proportion of patients treated on health service and the medical items which are not reusable make a hospital to produce wastes in volume.

According to [6], the improper managing of the HMW leads to serious problems of environmental health. In developing countries, it is a lack of compliance to regulation and not submissive to national or international best practices, even though the technologies are available, but they are too expensive. He also stated the readiness of infrastructure, lack of awareness, and knowledge triggered to the barrier for the correct management practice. The healthcare and medical activities commonly generate a variety of HMW [7]. If unmanaged well it will provoke trouble of health risks. Indonesia has a great population but lack of resource-constrained in handling the HMW.

Currently, a lot of articles published focus on the HMW context for developing countries. Most of them stressed the regulations and legislations related to HMW which are not accomplishments with the hospital activities in waste management [7]. According to [8], the countries are poor and harder to develop the HMW management system and lack a systematic approach to govern the waste programs. They also lack regulations and regulatory frameworks compliance to address the HMW treatment from producing until final disposal. Their inadequacies are in resources and the implementation of regulations and fragmented responsibilities among the government, stakeholders, and local authorities. Hence, the collection and management of the HMW are not aligned with the goals of the regulations itself as well as to reduce the high risks for social and environmental health.

As we have seen above, the problems of regulations and legislation are still not accomplishments into applied. The rules have variances regarding the kind of health care services. Hence, the health care institutions (primary, secondary, and tertiary) suffer from the HMW management from cradle-to-grave (the medical hazardous wastes are produce, collect, storage temporal or semi-permanent, transport, and finally disposal to dump). These practices can generate to environmental health risks. The awareness and knowledge regarding proper wastes represented the low of education and training for sanitarians or staff on duty. The HMW has threatened the environment and public health from extensive waste production, toxic, and infectious from incinerators of hospitals. According to [9], there are suggestions considering and giving much attention to hazardous and toxic wastes as materials generated from hospitals or healthcare facilities. The harmful effects on public health are the priority of concern to control. It has to become a major approach for getting attention to society's health environment. He stated that poor managing and conducting inappropriate methods exercised from cradle-to-grave stewardship will increase the significance of health hazards and risk pollutants into environment due to the infectious and pathogenic or toxic waste. Moreover, the concerns over these risks from the negative impacts of hazardous waste produced in hospitals have grown worldwide [10]. The previous studies reported, that great risks from medical waste to spread hazardous compounds and pathogens are similar to the toxic chemicals, nuclear and radioactive materials into the environment risks [11].

Overall, the developing counties faced a lot of challenges including Indonesia which has over 400 million people. Therefore, this research aims to determine the features required for KBS regarding the HMW problems. It will assist the stakeholders (government, third parties, hospitals, primary healthcare, the local authorities, and the societies) in reducing impacts between current practices and health protocols. It also gives alternatives for future HMW management and supports the policymakers in regulations improvement.

\section{Knowledge-Based Systems}

In view of the emerging AI technology, especially on the challenges of knowledge-based methods and techniques, we were studying the current state-ofthe-art KBS applications based on literature. We pay attention to the mechanism as an approach towards overcoming problematics and navigating uncharted HMW territories. It focused on developing knowledge modeling through top-down regulations approach under various legislations and different stakeholder's representations.

However, the design of a KBS is often not easy even for experienced knowledge engineers. There is necessity with respect to extensive knowledge and experience for representation from the experts, which are needed to determine the requirement of systems. To cope with the problems and challenges getting this, the requirement is needed to transform the protocols and regulations or tasks related to the setup of the HMW management into KBS. Hence, the respective knowledge of stakeholders needs to be collected according to disparate perspectives and heterogeneous formats. Referring to [12], who suggests that in order to cope with this challenging task is through semantic web technologies. It is allowed to successfully integrate respective building knowledge into the knowledge base. The system needs the formal basis of description logic for reasoning and search, thus a representation of a rigid formal description that can be matched with the purpose of knowledge requirement. The requirement of various knowledge can be configured into the method. It can be constructed-deployed if the data- 
information required inputs are correctly available. In the KBS, the process will automate to solve the problems, whereas in the traditional databases it can only be discovered by reading the database scheme [12].

According to [5], the knowledge-based supposed to reproduce human experience to automate against exceeding the expert's performance to leverage the waste knowledge for diagnoses. They are referred to be expert systems, decision support systems, data mining, etc. they can also be distinguished with their mechanism of inference. The main inferences are known as rule-based and case-based systems. The rule-based relies on the ruleset, whereas case-based on retrieval historical case as knowledge in interpretation. However, the number of available data or knowledge as a key for the knowledge-based on managing HMW is quite limited in Indonesia. This could potentially be due to improved data on medical waste and processes. It could be a useful and significant database of waste and reach the raised standards of the legislation target of government [1]. To create KBS for the HMW, an assessment of recent data and formulation of the protocol was conducted and referred to acts and regulations. The process systematically hunts to identify all of the relevance of data structure-attributes that compress from the basis of regulation. This activity defines the boundary of knowledge related to data objects and actors who are in charge and targeted to be users. The identification of the existing objects is compared to the activities and entities of stakeholders. All identification and determination are conducted using the data and information gathered which detailed in the methodology.

\section{The Act and Regulation of Hazardous Waste Knowledge-Based Systems}

Medical wastes have been categorized into hazardous and non-hazardous [13]. Hazardous is defined as various components that could be potential effects and harmful to the environment and human health such as chemical, toxic, infectious, pharmaceutical, radioactive, sharp, and other similar wastes. Meanwhile, non-hazardous refers to the components that are usually non-dangerous for the environment and human health. The environmental risks of hazardous waste and public health have been explored in several studies. Several acute diseases for public health have been reported, such as anthrax, hepatitis, and acquired immune deficiency syndrome (HIV/AIDS), and cholera human immunodeficiency virus infection. Moreover, the WHO estimates the situation of public health risks will increase according to the pandemic COVID-19, thus the unsafe usage of material in handling this pandemic (cloths, gloves, masks, medical treatment for test swab diagnosis, and other equipment poses on an annual global level more than 20 million infections of viruses including HIV, hepatitis B, and C [9]. Lastly, the pandemic of COVID-19 in developing countries raised in waves.

In Indonesia, there are already regulatory instruments at the national level and local authorities. Environmental Protection and Management (Law 32/2009) defines the Toxic and Hazardous Waste. It is the residue as a business of a healthcare institution and/or active medical test/treatment containing the HMW. It is further explained that the HMW management is an activity that includes production, reduction, storage, collection, transportation, utilization, processing, and/or landfilling. Next, Government Regulation 101/2014 concerning "Management of Hazardous and Toxic Waste", is a regulation on implementing HMW management at a more detailed level. This regulation defines the HMW management system which includes the definition of the producers, collectors, transporters, users, processors, and landfills of the HMW. The important point, the characteristics of the HMW are infectious. Regulation of the "Minister of Environment and Forestry (P.56/MenlhkSetjen/2015) concerning Procedures and Technical Requirements for Management of Hazardous and Toxic Waste from Health Service Facilities". It regulates the management of the HMW from health institution. The regulation is detailed arrangements for each of the HMW treatments intended for health facilities. It also provides guidance for the HMW generators since wastes produced. The Government Regulation 47/2016 is implementing on the Health (Law 36/2009). This law defines "A health service facility is a tool and/or place used to provide health service efforts, whether promotive, preventive, curative or rehabilitative carried out by the Government, the regional governments, and/or the community".

According to 101 of 2014, "infectious waste is a solid medical waste that is contaminated with pathogenic organisms that are not routinely present in the environment". These organisms are potentially sufficient quantity and virulence to transmit diseases to the human body who have a low immune and vulnerable. The infectious waste produced from waste originating from patient care that requires isolation of infectious diseases or intensive care, laboratory, the form of sharp objects such as syringes, intravenous equipment, Pasteur pipettes, and broken glass. The pathological waste can be produced from the surgical or autopsy process, culture and stock of infectious material, animal organs of experimental animals, other materials inoculated, and infected or in contact with highly infectious material. The cytotoxic waste is contaminated material from the preparation of cytotoxic drugs that are used for the treatment of chemotherapy for patients with cancer. It also stated the time to keep the material in storage with proper handling. Referring to Ministry Health Regulation 
No.1204/2004, the definition of solid medical waste is consisting of pathological, infectious, sharps, cytotoxic, pharmaceutical, chemical, pressurized containers, radioactive, and heavy metal content.

\section{Soft Systems Methodology (SSM)}

SSM was known as a structured methodology that used to solve the problematic environments by constructing organizational analysis. There are two main approaches to the SSM. First, the SSM aims to achieve organizational improvement change, which is considered to the culture, social, and politics of the situation on playing the important role in the organizational process. Second, SSM focused on application development, which is a strong emphasis on socio-cultural analysis which aims to produce the features of information systems required for an organizational context [14]. For these activities, the SSM involves the stakeholder's perspective (in a piece) and worldview to be depicted as a system model or represented the human activity system).

According to [15], the SSM has been widely used to help to problem-solve in many areas in research such as manufacture, industry, management, decision making, strategic planning, and so on. The SSM gives a framework to investigate a complex problem using System Thinking. It helps to solve the problem among stakeholders, owner, and user involved in System Thinking. Every human activity system is viewed as detailed to understand including those that are difficult to define. The SSM is more focused as a way to act or think every day and depict the realworld point of view in human thinking. The power of the SSM is a methodology to analyze the problem situation (unstructured and structured). It analyses the stakeholder roles and their relations in social, political, organizational management at all levels, and whatever influences them.

The sound of the SSM is easily adopted because it can apply for every problem situation as the founder mentioned [16]. He mentions the long way of the SSM history. The history began in 1972 with block and arrows, and in 1981 it detailed seven stages which are occasionally used by the authors. In 1988, the SSM was categorized into two streams. The parts of the SSM are finding out the problem situation (using rich picture and analysis), building a purposeful activity model (the role of modeling in the SSM, the root modelling CATWOE, and multi-level thinking, measure a performance, model building), and exploring the situation and taking action. At the end of his paper, he stated the SSM context into action research and the social process: appreciative systems. The action research produced the SSM to start out a base in system engineering. The appreciative systems are based on systems concept, whereas it took to be a process of social inquiry, aims to improvement, articulates a learning cycle, and leads into action. It can represent policymakers as regulators, establish the standards with simple description. He also stated the models are useful for any situation when the goals and measures are clear in performance. Thus, it is effective for communicating within people to achieve the goals. [16].

\section{Methods}

We adopted the four main key activities of the SSM. This study framework consists of five phases: (1) finding out the problem situation; (2) building a purposeful activity model, specifically on CATWOE; (3) model building KBS; (4) exploring the situation and taking action, focusing on the recommendation for stakeholders; and (5) reporting the results [16].

The study was concentrated more over 1 year due to institutional circumstances and a lot of departments involved. A sense for KBS requirement had arisen based on previous research which is to identify the problem of medical waste management in the Depok city. Afterwards, collecting data using semi-structured interviews, in-depth interviews, and questionnaires were conducted to evaluate the readiness of stakeholders in managing the HMW.

The regulation approach, collecting and review the laws, regulations, and legislations of the HMW was studied to get the context of the definition, subject, object, and process for a KBS. It was taken within 6 months, and the next 6 months following the commencement of the literature and documents. The bottom-up approach conducted to verify and confirm with interview mode as an action against the position, roles, and decision-makers. Four ministries and 1 province government were involved in this research. Furthermore, the FGD held into account the likely influence of other organizational processes and changes in finding out the problem situation. The FGD is also a method to get verification, confirmation, and validation.

\section{Results and Discussion}

The SSM aims to find out the problem situation comprehensively and sight it as a system. The process began with the identifying problem of waste management on 40 primary health care centers, 10 hospitals, 10 transporters, 5 disposal companies, 4 ministries, 10 departments in all provinces, local health practices communities (NGO), and 10 expertise of academicians. It is to illustrate the waste problems in the main cities i.e., Jakarta, Bogor, Depok, Tangerang, Bekasi, Medan, and Bali. These main cities are located at 5 Provinces of Indonesia (West Java, DKI Jakarta, Banten, Bali, and West Sumatera). 
The research objects consisted of the organizational healthcare (hospital, primary healthcare, laboratory, and clinics), the stakeholders, third parties (transporter, and disposal company), and the Government (ministry of health, ministry of environment, ministry of transportation, ministry of ICT, province, local authorities, and the NGOs).

The research conducted concurrently between SSM and regulation reviewed. The regulations are collected in a specific domain. It is focused on the hazardous solid medical waste which generates from healthcare organizations (hospitals and primary health care). Based on the subjects which are pointed on the regulation, we assigned the organization to be a part as stakeholders. We facilitated the stakeholders as participants and informants at various levels in the organizational hierarchy structure at their works. The policymaker and decision-maker pointed by the top level of their organization as representing of transporters and disposal companies. The supervisors of NGO are represented public and local health practice communities.

The strategic level and policymakers are more concerned with the compliance and/or noncompliance of regulations in the fields. The performance and regulation objective discussed including practices and operations for unit implementation. The gaps in information between stakeholders were revealed in this mode. They comprise of their experiences, expectation, and opinion in managing waste problems. Next, they agreed to be recorded as their respective in coordinating, monitoring, reporting, licensing, measuring, and improving the activities on the HMW management.

The stakeholders meeting conducted on FGD mode. Two FGD's were held in Depok and Jakarta. All participants are to be speakers at this meeting. They also wrote their problems, expectation, and experiences as the best practices for the regulations' implementation, actions, practices, and processing in their works. Finally, all stakeholders in advance discussed and presented the requirements of information systems for handling the HMW management and all crucial features come to a basis for the KBS.

\subsection{Phase 1: Representing the problem situation}

The existing main problems are mostly similar to the developing countries. They need improvement in reconciliation, adaptation, and compliance of regulations implementations with best practice in the fields. Most of them lack human resources with knowledge and skills competence in waste, health protocol, waste management, governance, standard regulation, and operation, licensing, stakeholders and partnership, waste technology, references, etc. There are no coordination stakeholders when the manifest of waste is transported from health institution into dump.

The main cities have different regulations from provinces and local authorities. This arouses to miscommunication among stakeholders. They do not know: when the HMW has been overproduced by the unit; how much its volume capacity is; when it will be transported by companies; what road is the route of the manifest; what kind of vehicles loaded the waste; where the manifest disposal is; and when the companies are ready to burn it depending on their volume of machines. The electronic manifest system exists for generating waste, transporters, and disposal. Unfortunately, the data and information still need to be synchronously integrated between client, users, decision-maker, and policymaker. These applications are only used for tracking and monitoring of licensed transporter and disposal companies. The systems waste management dispart and silo between local authorities and the central government. Hence, the communication and coordination are a mismatch for each regional authority. In this phase, the data and information summaries are depicted using object-oriented concepts needed by all users without changing the existing systems.

Table 1. The data object summaries for KBS

\begin{tabular}{|c|c|l|}
\hline No. & Data Object & \multicolumn{1}{c|}{ Descriptions } \\
\hline 1 & People & Doctors, sanitarians, academicians, decision-makers, policymakers, staff, etc. \\
\hline 2 & Things & $\begin{array}{l}\text { Injection, gloves, blood, needles, drain tubes, gauze, napkins, plastic syringes, swap, cotton, } \\
\text { and body parts, storage, dump, etc. and any other things which are categorized into material of } \\
\text { HMW [17]. }\end{array}$ \\
\hline 3. & Organization & $\begin{array}{l}\text { Ministries, Departments, Provinces, Local authorities, Hospitals, Primary Health Care, } \\
\text { Referral hospitals, Clinics, Laboratory, Pharmacy, Drugstore, collector company, transporters, } \\
\text { disposal companies, etc. }\end{array}$ \\
\hline 4. & Place & $\begin{array}{l}\text { Hospitals, Primary Health Care, Referral hospitals, Clinics, Laboratory, Pharmacy, Drugstore, } \\
\text { dumpsites, etc. }\end{array}$ \\
\hline 5. & Concept & $\begin{array}{l}\text { General waste, infectious waste, hazardous waste, medical waste, solid waste, liquid waste, } \\
\text { pharmaceutics, chemical, physical, pathological, toxicity [18], etc. }\end{array}$ \\
\hline
\end{tabular}




\subsection{Phase 2: Mapping the relevance of purposeful activity models}

The regulations were still not compliant and implemented well for each stakeholder. So, the data and information come to be a conflict for them. Who was responsible for data of the HMW manifest? The activities have to be mapped into models; the manifest data capacity loaded by transporter; the data maximum of volume tank disposal; the data place of the HMW to pool temporary before it burns; when the tank capacity is full; how long the tank is ready to use; where is the alternative of disposal companies; what emergency action follows if the transporter is facing trouble on the route; what is the alternative vehicle if it is not working properly; etc. So, we agree to elaborate on these conditions and system requirements into the complexity of the KBS. It has to be combined with other applications such as Geographic Information Systems (GIS), Data Mining, Text Mining, Decision Support Systems (DSS), and Artificial Intelligent (rule-based and casebased reasoning mechanism).

Another important issue, all data and information are not shared and integrated between stakeholders. These problems caused by the terminology of the regulations sometimes are not definitely similar for each management unit (the ministry of transportation, health, and environment). This study found that the vehicle with 2 wheels cannot bring the manifest, meanwhile, the position of primary health care service (hospital) was in a densely populated area and do not have access to vehicles in accordance with the regulations of the Ministry of transportation. Most of the vehicles should be fulfilled with the type of health protocol for the HMW. It also comes to be problem for the transporter because they only get the license for the big vehicles (more than 4 wheels). Hence, they are in conflict with the regulation's objective and stakeholders. The national regulations are derived into provincial regulations and then come to local authorities. Meanwhile, the routes of transportation are connected between the main cities (among province), whereas the disposal companies are located in the safety area (far away from main cities). This is the main gap between regulations and stakeholders. It lacks the functional and processing of systems features when getting actions into the area of conflict. Mostly, the stakeholders obtain their own data and information regarding the management unit issues. Whilst, the ICT based on KBS was massive applying to solve the complexity of problems, information conflict. The study suggests developing a KBS for the HMW management systems to get solutions at a systemic level. The CATWOE technique was conducted to represent the KBS data requirement $(\mathrm{C}=$ customer; $\mathrm{A}=$ actors; $\mathrm{T}=$ transformation process; $\mathrm{W}=$ worldview; $\mathrm{O}=$ owner; and $\mathrm{E}=$ environment). It was denoted a sequence and drawn using object-oriented attributes for the stakeholders and their worldview activities.

Table 2. The KBS data requirements based on CATWOE

\begin{tabular}{|c|c|c|}
\hline No. & CATWOE & Descriptions \\
\hline 1 & Costumers & Public and private users that interact within the systems \\
\hline 2 & Actors & Stakeholders, Partners, and Government \\
\hline 3 & $\begin{array}{l}\text { Transformation } \\
\text { Process }\end{array}$ & $\begin{array}{l}\text { "Health Protocol; Waste Management; A waste survey (it should be undertaken about the } \\
\text { information on the waste planning process, which provide information on types and quantity of } \\
\text { wastes, and kind of arising at each point of production, and methods of storage, handling, treatment, } \\
\text { and disposal)". } \\
\text { [18]: "Generation, treatment, storage, and disposal; effect of health". } \\
\text { [19]: "Treatment methods; Use of Private Medical Waste-Haulers; Pour into Municipal Sewage } \\
\text { System; Depositing in Landfills; Autoclaving; ETDTM (Macrowaving); Chemical Disinfecting or } \\
\text { Hydropulping; Microwaving; Grind before Pour into Municipal-Sewage System; Irradiation". }\end{array}$ \\
\hline 4 & Worldview & $\begin{array}{l}\text { All stakeholders involved have a responsibility which is transparent, accountable, and participative. } \\
\text { National, Provincial, and Local Authorities regulations according to HMW } \\
\text { [17]: "Waste category". } \\
\text { [19]: "State Regulations, Occupational, Centers for Disease Control and Prevention (CDC), } \\
\text { Occupational Safety and Health Administration (OSHA), Nuclear Regulatory Commission (NRC), } \\
\text { Joint Commission on Accreditation of Healthcare Organizations (JCAHO), the American Hospital } \\
\text { Association (AHA), and the Agency for Toxic Substances and Disease Registry (ATSDR), } \\
\text { American Medical Association (AMA) or American Practitioner of Infection Control Association } \\
\text { (APIC)". } \\
\text { [20]: "Regulatory framework, Medical waste characteristics, Medical waste management and } \\
\text { disposal activities, Health implications of managing medical waste, and Medical waste disposal } \\
\text { issue". } \\
\text { [21]: "Medical waste tracking act (MWTA), Resource Conservation and Recovery Act (RCRA), and } \\
\text { Environmental Protection Agency (EPA)". }\end{array}$ \\
\hline 5 & Owner & Government (Ministries), and stakeholders \\
\hline 6 & Environment & $\begin{array}{l}\text { Ecological Environment, Health Public Environment, Ethics and Professional Code, Political } \\
\text { willingness, and all trusted users }\end{array}$ \\
\hline
\end{tabular}




\subsection{Phase 3: Discussing the situation using the models}

After a conceptual modelling of represented CATWOE had been completed, a kind of workshop (FGD) was held to debate the draft of concept models with stakeholders. The stakeholder's corrected the models of KBS which is needed for integrating systems in the future. The priorities of infrastructure technologies have to be concerned in mature. Despite, the technologies are ready, it should align with the road map of HMW and comply with health care facilities [22]. The stakeholders are agreeing to exchange, transfer, and transform the knowledge according to the KBS mechanism. The infrastructure specification will be negotiated between stakeholders. The CATWOE was used to produce business process management for improving the HMW governance. Furthermore, this phase is a moment to gather the commitment of stakeholders in continuing the program of KBS for the HMW into recommendation and posting as strategical planning next year. This research will be continued into sophisticated of ICT for HMW. So, it can be easier to be deployed in organizations. The program is going to be discussed frequently to improve the regulations across levels (practical, managerial, and strategical role). Hence, the coordination will be established in units, departments, ministries, and parties.

\subsection{Phase 4: Taking action for solving and improving the situation}

Referring to [23] we believed that SSM has unique features for organizational improvement. It can depict the context and provide guidance to identify the important factor which should be assessed, so the link between stakeholders can be determined into their system requirements (data and knowledge). The splits of the influencing factors, causal-effects, problems, and parts of the system from each other will be avoided. The SSM will help assist in defining the interaction and intervention to contribute before the actual implementation because it is a straightforward process about improvement. The SSM is able to depict and establish a knowledgebased similar to systems-based (as a way to use system concepts in organizations) for making interaction, interventions and understanding their efforts [24].

Finally, all phases of SSM lead and unite the coordination of stakeholders. They are agreeing to establish the actions of managing the HMW since it is produced, collected, stored, transported, and disposal. They promised to be committed to complying with regulations and improving into good practice and the HMW governance. They believed if KBS could develop as systems integrated, it will support the decision-maker and police maker better in monitoring and controlling the implementation of regulations in the fields. Thus, the stakeholders will be assisted in their works, so the problems of the HMW will be reduced and handled properly and in compliance with national regulations.

\section{Conclusion}

A combining method of SSM and the regulations approach was done to identify the features of the KBS comprising of data, information, and knowledge source. It can be applied, enhanced, and extended to the HMW management. The features of the KBS requirement are represented into CATWOE technique. The features can be implemented using a rule-based and case-based mechanism. The rule-based is suitable for regulatory and standardizations, whereas the case-based is corresponding for hazardous evidence in the environment. The authors find out that the KBS for HMW is very complex. It is mainly reaching against the network among stakeholders and partnerships pointed. The regulations are developed in compliance with the WHO standards, but in practice, it needs to be monitored and ensures the practical handling of specimens in the fields. The resources consisted of objects with attributes including people, place, things, organization, and concept. The staff, partnerships (transporters, and disposal companies), and the surrounding society environment come out to the potential of the KBS resources. The processing of manifest since it is produced, collected, stored, transported, and disposed (from cradle to grave) need elaborating and properly managing to minimize public health risk. The KBS has to cover the emerging of waste destruction technology. Meanwhile, this study focused on features' requirement and data attributes as on the CATWOE. The impact of produced material on environmental ecology has to be revealed in future research because it can contaminate air, water, landfill, and human health. It can be a pollutant and come to the toxic. Stakeholders should have the initiative to monitor the process of the HMW management periodically. This can be supported by the relevance of information and the KBS in sophisticated technology.

Certainly, this paper has limitations. The regulations and legislations approach focused on the main umbrella of the HMW management in Indonesia. The knowledge attributes have to explore deeply into detail composition. Thus, future research has to consist of widespread organization that produces the HMW. The rich knowledge needs to be elaborated for applying the mechanism of the KBS. A longitudinal design could be taken in monitoring the KBS development. 


\section{Acknowledgements}

The authors gratefully acknowledge to Ministry of Research of Indonesia in Basic Research for Higher Education Scheme with "Decentralization Research Competition Fund" No. 11/AKM/PNT/2019. Special thanks to several Ministries and Departments involving as stakeholders, the third parties which partnership of healthcare institutions, Jakarta Provincial Government, and all of the support to this research.

\section{References}

[1]. Harastani, R., James, L. J., Walton, J., \& Woolley, E. (2020). Tackling obesity: A knowledge-base to enable industrial food reformulation. Innovative Food Science \& Emerging Technologies, 64, 102433.

[2]. Inan, D. I., Beydoun, G., \& Pradhan, B. (2018). Developing a decision support system for Disaster Management: Case study of an Indonesia volcano eruption. International journal of disaster risk reduction, 31, 711-721.

[3]. Bolukbas, U., \& Guneri, A. F. (2018). Knowledgebased decision making for the technology competency analysis of manufacturing enterprises. Applied Soft Computing, 67, 781-799.

[4]. Choy, K. L. T., Siu, K. Y. P., Ho, T. S. G., Wu, C. H., Lam, H. Y., Tang, V., \& Tsang, Y. P. (2018). An intelligent case-based knowledge management system for quality improvement in nursing homes. VINE Journal of Information and Knowledge Management Systems, 48(1), 103-121.

[5]. Burggräf, P., Wagner, J., \& Weißer, T. (2020). Knowledge-based problem solving in physical product development-A methodological review. Expert Systems with Applications: X, 5, 100025.

[6]. Ahmad, R., Liu, G., Santagata, R., Casazza, M., Xue, J., Khan, K., ... \& Lega, M. (2019). LCA of hospital solid waste treatment alternatives in a developing country: the case of district Swat, Pakistan. Sustainability, 11(13), 3501.

[7]. Ali, M., Wang, W., Chaudhry, N., \& Geng, Y. (2017). Hospital waste management in developing countries: A mini review. Waste Management \& Research, 35(6), 581-592.

[8]. Mmereki, D., Baldwin, A., Hong, L., \& Li, B. (2016). The management of hazardous waste in developing countries. Management of Hazardous Wastes, 6(8), 39-50.

[9]. Ansari, M., Ehrampoush, M. H., Farzadkia, M., \& Ahmadi, E. (2019). Dynamic assessment of economic and environmental performance index and generation, composition, environmental and human health risks of hospital solid waste in developing countries; A state of the art of review. Environment international, 132, 105073 .
[10]. Windfeld, E. S., \& Brooks, M. S. L. (2015). Medical waste management-A review. Journal of environmental management, 163, 98-108.

[11]. Ghasemi, M. K., \& Yusuff, R. B. M. (2016). Advantages and disadvantages of healthcare waste treatment and disposal alternatives: Malaysian scenario. Polish Journal of Environmental Studies, 25(1).

[12]. Schneider, G. F., Kontes, G. D., Qiu, H., Silva, F. J., Bucur, M., Malanik, J., ... \& Grün, G. (2020). Design of knowledge-based systems for automated deployment of building management services. Automation in Construction, 119, 103402.

[13]. WHO. (2018). Health-care waste. WHO.

Retrieved from: https://www.who.int/newsroom/fact-sheets/detail/health-care-waste . [accessed: 28 June 2021].

[14]. Cox, S. A., \& Kirkham, S. (2019). Understanding the Contribution and Challenges of Using Soft Systems Methodology to Facilitate Cultural Change: A Case Study in the Public Sector. In Organizing for the Digital World (pp. 215-234). Springer, Cham.

[15]. Aldianto, L., Novani, S., Anggadwita, G., Budi, A. A., \& Wirawan, C. (2020). Soft system methodology approach: tourism conceptual model as the identity of Bandung, Indonesia. Business: Theory and Practice, 21(1), 282-292.

[16]. Checkland, P. (2000). Soft systems methodology: a thirty year retrospective. Systems research and behavioral science, 17(S1), S11-S58.

[17]. Almuneef, M., \& Memish, Z. A. (2003). Effective medical waste management: it can be done. American journal of infection control, 31(3), 188-192.

[18]. Muralikrishna, I. V., \& Manickam, V. (2017). Hazardous waste management. Environmental Management, 463-494.

[19]. Klangsin, P., \& Harding, A. K. (1998). Medical waste treatment and disposal methods used by hospitals in Oregon, Washington, and Idaho. Journal of the Air \& waste management Association, 48(6), 516-526.

[20]. Wagner, K. (1991). Medical Waste Management. Environmental Science \& Technology, 25(6), 994-994.

[21]. Studnicki, J. (1992). The management of hospital medical waste: How to increase efficiency through a medical waste audit. Hospital topics, 70(2), 11-17.

[22]. Ministry of Environtment and Forestry. (2018). Peta Jalan (Roadmap) Pengelolaan Limbah B3 dari Fasilitas Pelayanan Kesehatan (Fasyankes). Direktorat Penilai. Kinerja Pengelolaan Limbah B3 dan Limbah Non B3, Kementeri. Lingkung. Hidup dan Kehutanan.

[23]. Augustsson, H., Churruca, K., \& Braithwaite, J. (2019). Re-energising the way we manage change in healthcare: the case for soft systems methodology and its application to evidence-based practice. BMC health services research, 19(1), 1-11.

[24]. Sgourou, E., Katsakiori, P., Papaioannou, I., Goutsos, S., \& Adamides, E. (2012). Using soft systems methodology as a systemic approach to safety performance evaluation. Procedia Engineering, 45, 185-193. 